Published in final edited form as:

Adv Healthc Mater. 2018 February ; 7(3): . doi:10.1002/adhm.201700701.

\title{
Glycan Stimulation Enables Purification of Prostate Cancer Circulating Tumor Cells on PEDOT NanoVelcro Chips for RNA Biomarker Detection
}

\section{Dr. Mo-Yuan Shen,}

Smart Organic Material Laboratory, Institute of Chemistry, Academia Sinica, No. 128, Sec. 2 , Academia Rd., Nankang, Taipei 11529, Taiwan

\section{Dr. Jie-Fu Chen,}

Samuel Oschin Comprehensive Cancer Institute, Cedars-Sinai Medical Center, 8700 Beverly Blvd., Los Angeles, CA 90048, USA

\section{Chun-Hao Luo,}

Smart Organic Material Laboratory, Institute of Chemistry, Academia Sinica, No. 128, Sec. 2 , Academia Rd., Nankang, Taipei 11529, Taiwan

\section{Dr. Sangjun Lee,}

Department of Molecular and Medical Pharmacology, California NanoSystems Institute,

University of California, Los Angeles, 570 Westwood Plaza, Los Angeles, CA 90095-1770, USA

\section{Cheng-Hsuan Li,}

Smart Organic Material Laboratory, Institute of Chemistry, Academia Sinica, No. 128, Sec. 2 , Academia Rd., Nankang, Taipei 11529, Taiwan

\section{Yung-Ling Yang,}

Smart Organic Material Laboratory, Institute of Chemistry, Academia Sinica, No. 128, Sec. 2 , Academia Rd., Nankang, Taipei 11529, Taiwan

\section{Yu-Han Tsai,}

Smart Organic Material Laboratory, Institute of Chemistry, Academia Sinica, No. 128, Sec. 2 , Academia Rd., Nankang, Taipei 11529, Taiwan

\section{Bo-Cheng Ho,}

Department of Material Engineering, Ming Chi University of Technology, 84 Gungjuan Rd., Taishan Dist., New Taipei City 24301, Taiwan

\section{Li-Rong Bao,}

Department of Molecular and Medical Pharmacology, California NanoSystems Institute, University of California, Los Angeles, 570 Westwood Plaza, Los Angeles, CA 90095-1770, USA

Tien-Jung Lee,

Correspondence to: Shuang Hou; Vatche Agopian; Yu-Sheng Hsiao; Hsian-Rong Tseng; Edwin M. Posadas; Hsiao-hua Yu. 
Department of Molecular and Medical Pharmacology, California NanoSystems Institute, University of California, Los Angeles, 570 Westwood Plaza, Los Angeles, CA 90095-1770, USA

Dr. Yu Jen Jan,

Department of Molecular and Medical Pharmacology, California NanoSystems Institute, University of California, Los Angeles, 570 Westwood Plaza, Los Angeles, CA 90095-1770, USA

Dr. Ya-Zhen Zhu, Department of Molecular and Medical Pharmacology, California NanoSystems Institute, University of California, Los Angeles, 570 Westwood Plaza, Los Angeles, CA 90095-1770, USA

\section{Shirley Cheng,}

Samuel Oschin Comprehensive Cancer Institute, Cedars-Sinai Medical Center, 8700 Beverly

Blvd., Los Angeles, CA 90048, USA

\section{Prof. Felix Y. Feng,}

Departments of Radiation Oncology, Urology, and Medicine, University of California, San

Francisco, San Francisco, CA 94158 USA

\section{Dr. Peilin Chen,}

Research Center for Applied Sciences, Academia Sinica, Taipei 11529, Taiwan

\section{Dr. Shuang Hou,}

Liver Transplantation and Hepatobiliary Surgery, Department of Surgery, David Geffen School of Medicine at UCLA, Los Angeles, CA 90095, USA

\section{Prof. Vatche Agopian,}

Liver Transplantation and Hepatobiliary Surgery, Department of Surgery, David Geffen School of Medicine at UCLA, Los Angeles, CA 90095, USA

\section{Prof. Yu-Sheng Hsiao,}

Department of Material Engineering, Ming Chi University of Technology, 84 Gungjuan Rd., Taishan Dist., New Taipei City 24301, Taiwan

Prof. Hsian-Rong Tseng,

Department of Molecular and Medical Pharmacology, California NanoSystems Institute, University of California, Los Angeles, 570 Westwood Plaza, Los Angeles, CA 90095-1770, USA

Dr. Edwin M. Posadas, and

Samuel Oschin Comprehensive Cancer Institute, Cedars-Sinai Medical Center, 8700 Beverly Blvd., Los Angeles, CA 90048, USA

\section{Dr. Hsiao-hua Yu}

Smart Organic Material Laboratory, Institute of Chemistry, Academia Sinica, No. 128, Sec. 2 , Academia Rd., Nankang, Taipei 11529, Taiwan

\section{Abstract}

A glycan-stimulated and poly(3,4-ethylene-dioxythiophene)s (PEDOT)-based nanomaterial platform is fabricated to purify circulating tumor cells (CTCs) from blood samples of prostate cancer (PCa) patients. This new platform, phenylboronic acid (PBA)-grafted PEDOT NanoVelcro, combines the 3D PEDOT nanosubstrate, which greatly enhances CTC capturing efficiency, with a 
poly(EDOT-PBA-co-EDOT-EG3) interfacial layer, which not only provides high specificity for CTC capture upon antibody conjugation but also enables competitive binding of sorbitol to gently release the captured cells. CTCs purified by this PEDOT NanoVelcro chip provide well-preserved RNA transcripts for the analysis of the expression level of several PCa-specific RNA biomarkers, which may provide clinical insights into the disease.

\section{Keywords}

circulating tumor cells; poly(3,4-ethylene-dioxythiophene)s; prostate cancer; responsive materials; RNA biomarkers

Circulating tumor cells (CTCs) are rare cancer cells shed or detached from solid tumors into the blood stream. Prospective clinical trials have shown the value of CTCs as clinical biomarkers where counts associate with survival and changes in number associate with response to therapy in solid tumors such as melanoma, ${ }^{[1]}$ breast, ${ }^{[2]}$ colorectal, ${ }^{[3]}$ lung, ${ }^{[4]}$ and prostate cancer (PCa). ${ }^{[5]}$ Beyond enumeration, CTCs themselves are now being studied as an alternative tissue source creating a foundation for a "liquid biopsy." This holds the potential to conduct contemporary molecular characterizations that can provide insights into a cancer when tumor biopsy is difficult and/or dangerous to perform. ${ }^{[6]}$ Recent research endeavors demonstrated the feasibility of CTC-based detection of clinically relevant molecular signatures, such as mutations in $E G F R,{ }^{[7]} B R A F{ }^{[8]}$ and $K R A S$ genes. ${ }^{[8]}$ In addition to the DNA mutations, CTC-based measurement of gene expression has also been explored. This is particularly important in PCa where there is a relatively low abundance of DNA mutations in tumors. ${ }^{[9]}$ In PCa and other malignancies, many have focused efforts on characterization of gene expression and other RNA biomarkers. ${ }^{[10]}$ In addition to more conventional genes, newer noncoding RNAs such as long non-coding RNAs (lncRNA) are showing even greater prognostic value in PCa. Expression of SChLAP1 in PCa tumors was linked to higher risk of metastasis. ${ }^{[1]}$ Profiling of clinically and biologically relevant RNA biomarkers in PCa CTCs has been reported: higher expression of FOLH1 (prostate specific membrane antigen, PSMA) in CTCs is associated with more aggressive disease. ${ }^{[12]}$ Studies of androgen receptor (AR) splicing variants in CTCs reveal that the expression of $A R-V 7$ in CTCs predicts the resistance to abiraterone and enzalutamide. ${ }^{[13]}$ However, despite the enormous research efforts in CTC-based molecular testing, it remains technically challenging for existing platforms to efficiently obtain high-quality signals due to the low abundance of CTCs and the fragility of the genetic materials. To address this issue, new technologies capable of capturing and releasing CTCs with minimal contamination of white blood cells (WBCs) and maximal cellular viabilities and molecular intactness are needed.

A cell-affinity substrate using a unique concept called "NanoVelcro" was pioneered by us. ${ }^{[14,15]}$ On this capture agent-coated nanostructured substrates substrate, we were able to selectively sort and purify the cells of interest (e.g., CTCs) from background cells with high efficiency. When the hairy nanostructured substrate meet the rough cancer cell surfaces, stronger binding occurred, which mimicked the working mechanism of Velcro strips. Other researchers also started to test the utilities of different nanostructure-embedded substrates ${ }^{[16]}$ for capturing CTCs and other types of rare cells since our proof-of-concept publication in 
$2009,{ }^{[17]}$ and these works support the general applicability of nanostructure-embedded cellaffinity assays and their potential for cell-sorting applications. Among the materials which have been engineered into nanostructured substrates, poly(3,4-ethylenedioxythiophene) (PEDOT $)^{[18]}$ is promising given their advantages in easy introduction of functional groups through covalent bonds ${ }^{[19]}$ and compatibility with various nanoengineering approaches. ${ }^{[20]}$ We have demonstrated highly efficient CTC capturing on NanoVelcro chips with electropolymerized PEDOT nanodots ${ }^{[21]}$ and nanoimprinted PEDOT rods array. ${ }^{[22]}$

On the basis of nanostructure-embedded substrates that exhibit enhanced cell-capture affinity, we and others previously introduced stimuli-responsive materials onto the nanosubstrates ${ }^{[23,24]}$ to enable "on-demand" release of the captured CTCs for downstream molecular analyses. In most cases, the captured cells were released by various physical ${ }^{[25]}$ and biological mechanisms. ${ }^{[26]}$ However, some external stimuli pose a harsh condition in which the genetic content of CTCs can be altered and lead to the incorrect information in molecular analysis, particularly in the cases of vulnerable genetic materials such as RNA. ${ }^{[23]}$ As such, there is unmet need to develop an efficient CTC purification technology using a physiologically compatible stimulus, which will provide higher quality RNA for characterization.

Herein, we introduce a new CTC purification platform based on a phenylboronic acid (PBA)-grafted PEDOT NanoVelcro chip. In this platform, the covalently grafted PBA groups allow direct conjugation of antibody (i.e., anti-EpCAM) onto a PEDOT nanosubstrate via PBA-oligosaccharide bonding, enabling specific capture of CTCs (Figure 1a). Upon exposure to a glycan molecule (i.e., sorbitol) which has a stronger affinity to PBA, [27] competitive binding leads to release of the captured CTCs (Figure 1b). Through the affinity capture, followed by the "on-demand" release with minimal changes in the microenvironments, CTCs can be purified with their RNA better preserved. We then demonstrated the measurement of RNA biomarkers in purified CTCs from PCa patients focusing on $A R-F L, A R-V 7, K L K 3, F O L H 1$, and $S C h L A P 1$ using the work-flow illustrated in Figure 1c.

Given the advantages of high conductivity, ${ }^{[18]}$ stability in aqueous solutions, ${ }^{[28]}$ and low toxicity, ${ }^{[29]}$ PEDOTs have been incorporated into the interface between biology systems and electronic devices (e.g., biosensors ${ }^{[30]}$ and medical devices ${ }^{[31]}$ ). Choosing PEDOT as the base material provides us an easy access to meet the molecular and nanostructural requirements to build the cell purification platform. Once the PEDOT monomers are properly functionalized using organic synthetic approaches, electropolymerization utilizing PEDOTs' conductive nature gave us a quick $(<1 \mathrm{~min})$ and highly reproducible approach to functionalize all conductive nanosubstrates, meeting the cellular needs. As shown in Figure 2a, a PBA-grafted PEDOT NanoVelcro Chip was prepared by a simple two-step procedure: (1) nanoimprinting of the PEDOT rods array, followed by (2) electrochemical deposition of PBA-grafted PEDOT layer (i.e., poly(EDOT-PBA-co-EDOT-EG3)) in a solution containing two monomer precursors (i.e., EDOT-EG3 and EDOT-PBA). EDOT-PBA introduced the covalently grafted PBA groups to control the capture and release of CTC (Figure 1a,b). The other unit, EDOT-EG3, played a critical role in reducing the nonspecific binding of nontargeted cells and facilitating CTC release from the chips upon sorbitol exposure. ${ }^{[32]}$ 
Images taken by scanning electron microscopy (SEM) confirmed the structures of nanoimprinted PEDOT rods array as shown in Figure 2b. The nanoimprinting and subsequent deposition of PBA-functionalized PEDOT layer were also confirmed by X-ray photoelectron spectroscopy (XPS). Once the PEDOT rods array was imprinted, we could observe the characteristic peaks from the chip, including $\mathrm{O} 1 \mathrm{~s}$ electrons from ether groups, $\mathrm{C}$ 1s electrons from all $-\mathrm{CH}_{2}-$ and $-\mathrm{CH}-$ linkers and $\mathrm{S} 2 \mathrm{~s}$ and $2 \mathrm{p}$ electrons from thiophenes (Figure S3, Supporting Information). Upon electropolymerizing the poly(EDOT-PBA-coEDOT-EG3) layer, the detection of new peaks from B 1s $(190.4 \mathrm{eV})$ and $\mathrm{N} 1 \mathrm{~s}(399.2 \mathrm{eV})$ confirmed the polymer deposition as shown in Figure 2c. Energy-dispersive X-ray spectroscopy (EDX, Figure S4, Supporting Information) on the sample showed that boron signal was evenly detected, suggesting the electropolymerization occurred on all surface of the chip.

Unlike an earlier report which utilized PBA to recognize sialic acid on cancer cell surfaces, ${ }^{[33]}$ we applied surface PBAs to form conjugates with the oligosaccharide residues on antibodies (i.e., anti-EpCAM) to capture CTC. We used quartz crystal microbalance experiments to confirm our central molecule scheme, bioconjugation, and sorbitolstimulated release of antibodies on PBA-functionalized polymer. When the polymer is prepared completely from EDOT-PBA, we were able to achieve a density of $319 \pm 8 \mathrm{ng} \mathrm{cm}$ -2 of the conjugated antibodies as shown in Figure 2d, but only $51 \pm 0.01 \%$ of the antibodies were released in sorbitol solution $(n=3)$. This was most likely due to the nonspecific interactions between the polymer and antibodies, prohibiting the release of antibodies after the oligosaccharide-PBA binding was replaced by the stronger sorbitol-PBA interaction. ${ }^{[32,34]}$ As mentioned earlier, introduction of EDOT-EG3 unit to the polymer limited the nonspecific absorptions of proteins and cells, thereby enhancing both the capture specificity and release yield. When EDOT-PBA and EDOT-EG3 were copolymerized, the surface density of conjugated antibodies correlated positively with the feed percentage of EDOT-PBA, and we noted a sharp increase of antibody release from below $60 \%$ to almost $100 \%$ with the feed percentage of EDOT-EG3 greater than $50 \%$ (Figure 2d). ${ }^{[32,34]}$ Based on these results, the polymer composed from EDOT-EG3 and EDOT-PBA at 1:1 feed ratio showed optimal performance, combining high surface density of capture antibodies with almost complete release after sorbitol exposure (Figure S6, Supporting Information). This optimized composition was then used for the PBA-grafted NanoVelcro chip fabrication for in vitro cellular and clinical sample studies.

The synergistic effect of nanostructures and capture antibodies has been proven to enhance the CTC capture performance. We previously reported that 3D PEDOTs can successfully capture CTCs through biotinylated anti-EpCAM and streptavidin-modified interface with great efficiency. ${ }^{[21,22]}$ Using the PBA-grafted PEDOT NanoVelcro chips, we also observed that anti-EpCAM-conjugated PEDOT NanoVelcro chip exhibited much higher capture efficiency $(72.5 \pm 3.0 \%, n=3, p<0.0001)$ for EpCAM-positive LNCaP cells, as compared to the nonconjugated PEDOT NanoVelcro chip, nonconjugated PEDOT (composed by poly(EDOT-PBA-co-EDOT-EG3)) film, and anti-EpCAM-conjugated PEDOT film (Figure 3a). As expected, the anti-EpCAM-conjugated PEDOT NanoVelcro also exhibited significantly higher capture efficiency ( $p<0.001$ for each comparison) for other EpCAMpositive PCa cells $(75.2 \pm 3.2 \%$ for PC 3 , and $67.8 \pm 1.7 \%$ for $22 \mathrm{Rv} 1, n=3$ for each cell 
line) compared to EpCAM-negative WBCs $(0.01 \pm 0.004 \%, n=3$, Figure $3 b)$. When we optimized the capture efficiency by varying the incubation time, it plateaued at $60 \mathrm{~min}$ as shown in Figure 3c. The performance of CTC capturing remained consistent in spiking study (Figure 3d) within the tested range of 1-2000 PCa cells spiked into healthy human blood. The capture efficiency for 22Rv1 cells was constantly lower than that for LNCaP or PC3 cells, likely due to the technical difficulties in cell counting resulted from cell aggregation.

After optimizing the capture performance, we continued to search experimental conditions for optimal cell release using sorbitol solution. As shown in Figure 3e, the cells could be released most efficiently with $0.5 \mathrm{M}$ sorbitol solution ( $p<0.05$ in comparison to $0.25 \mathrm{M}, n=$ $3)$. Although the release efficiency of $1 \mathrm{M}$ sorbitol solution was not significantly lower than that of $0.5 \mathrm{M}$ solution, cell damage was observed at concentration greater than $1 \mathrm{M}$, possibly due to the change in osmolality. Further optimization (Figure 3f) revealed that the highest release efficiency $(95 \%)$ and cell viability $(96 \%)$ were achieved by incubating the cells in 0.5 $\mathrm{M}$ sorbitol solution for $30 \mathrm{~min}$. Incubation for more than $30 \mathrm{~min}$ did not increase the release efficiency significantly but decreased the cell viability, possibly due to the prolonged exposure to unfavorably high osmotic environment. In order to examine the PBA-grafted PEDOT NanoVelcro chips for CTC enrichment in samples from cancer patients, we incubated an artificial sample of $200 \mathrm{LNCaP}$ cells spiked into 1 million WBCs on the chip. As shown in the representative experiment, only 3141 cells were captured after the chip was washed to remove unbound cells (Figure 3g). Among these cells, 141 were LNCaP cells ( $71 \%$ of the original $\mathrm{LNCaP}$ cell population) compared to $3000 \mathrm{WBCs}(0.3 \%$ of the original WBC population). The differential binding affinity could be attributed to the introduction of cell-resisting EDOT-EG3 monomer, which decreased the binding of WBCs, and the use of capture antibodies, which specifically captured LNCaP cells. Upon the treatment with $0.5 \mathrm{M}$ sorbitol, 132 captured $\mathrm{LNCaP}$ cells (94\% of the captured $\mathrm{LNCaP}$ population) were released together with 154 nontargeted WBCs (5\% of the captured WBC population). The most advantageous feature of this PBA-grafted PEDOT NanoVelcro chip is that within a single capturing and releasing cycle, the purity of the CTC enhanced from the original 0.02 to $46 \%$. The cells showed $98 \%$ viability on-chip and $95 \%$ after stimulated release from the PEDOT NanoVelcro chip (Figure S7, Supporting Information). The increased purity and high cell viability would be beneficial for the subsequent molecular and biochemical analysis.

Using the PBA-grafted PEDOT NanoVelcro chips under operating conditions optimized from the aforementioned studies, we purified CTCs from clinical blood samples and measured the expression of PCa-related RNA biomarkers. Samples were obtained from 17 PCa patients (13 metastatic and 4 localized) and 7 healthy individuals with no known malignancies. The methods for reverse transcription (RT) and quantitative PCR (qPCR) were developed using serially diluted PCa cell lines to ensure the linear correlation (Figure S9, Supporting Information). The expression level of each PCa-related biomarker was normalized against that of house-keeping gene $A C T B$. Enumeration of CTCs was performed in parallel to confirm the presence of CTCs.

Expression data for five PCa-related biomarkers from all 24 subjects were summarized in Figure 4a. Every patient $(n=17)$ had at least one CTC upon enumeration (Figure S10, 
Supporting Information). We detected PCa-related biomarkers in CTCs from 94\% of patients (16/17). Consistent with previous reports, ${ }^{[35-37]}$ the expression of $K L K 3$ (prostatespecific antigen, PSA) was seen in $77 \%$ of metastatic patients (10/13) as compared to only $25 \%$ of the nonmetastatic PCa patients (1/4) (Figure 4b). The expression of FOLH1 and $S C h L A P 1$ was detected exclusively in metastatic PCa patients. FOLH1 expression in CTCs was detected in $85 \%$ of metastatic PCa patients (11/13) (Figure 4c), and SChLAP1 was detected in $92 \%$ of the same patient group (12/13) (Figure 4d). This is the first demonstration of $S C h L A P 1$ expression in CTCs. Our results suggest that $S C h L A P 1$ detection in CTCs may have a similar role as that in primary tumor tissues. Figure $4 \mathrm{e}$ depicted wild-type $A R$ (AR-FL) expression and $A R-V 7$. Consistent with prior observation, $A R-V 7$ was always detected in the presence of $A R-F L$. Our results showed $A R-V 7$ in $75 \%$ of the patients $(6 / 8)$ who had been exposed to abiraterone and/ or enzalutamide. Interestingly, in the abiraterone and enzalutamide naïve patients, $A R-V 7$ was seen in $60 \%$ of subjects (3/5). Our detection rate for $A R-V 7$ was higher than some previous reports though others have reported even higher rates. ${ }^{[38]}$ This reflected differences in the CTC enrichment approach (PEDOT-NanoVelcro Chips vs no enrichment) and methodology of $A R-V 7$ detection (direct RNA detection via qRT-PCR vs antibody-mediated immunofluorescence staining). Other factors such as the exposure to other anticancer treatments after AR-targeted therapy may have affected the expression of $A R-V 7$ in CTCs as well. ${ }^{[39]}$ Notably, we also detected $A R-V 7$ in patients with localized PCa. The clinical significance of $A R-V 7$ in these patients has yet to be determined. The $A R-V 7(+)$ patients in this study continue to be monitored for the development of resistance. Further studies are required to validate the sensitivity and clinical utility of this assay.

In summary, we introduce an innovative approach for CTC purification using a new PBAgrafted PEDOT NanoVelcro chip, integrating the advantageous features of nanoimprinted 3D PEDOT rods array, which demonstrates the ability to enhance CTC capture, and a poly(EDOT-PBA-co-EDOT-EG3) layer, which not only provides highly selective CTC capture by conjugation with antibodies through phenylboronic-acid-oligosaccharide binding but also enables competitive glycan binding to release the captured cells. As a result, this PEDOT NanoVelcro chip is able to achieve high cell purity as well as preserve the integrity of RNA transcripts from these purified cells. We further demonstrate the feasibility of this approach to detect disease-related RNA signals by measuring the expression level of several PCa-specific biomarkers in purified CTCs, including $A R-F L, A R-V 7, K L K 3, F O L H 1$, and $S C h L A P 1$. This capacity provides important opportunities for clinical correlation.

\section{Supplementary Material}

Refer to Web version on PubMed Central for supplementary material.

\section{Acknowledgments}

M.-Y.S., J.-F. and C.-H. L contributed equally to this work. The research endeavors at Academia Sinica were supported by the Ministry of Science and Technology (MOST) of Taiwan (MOST-104-2113-M-001-025-MY2) and by the Academia Sinica Research Project on Nano Science and Technology and Academia Sinica Thematic Project. The research endeavors at Cedars-Sinai Medical Center were supported by a DoD Idea Award (W81XWH-11-1-0422) and Postdoctoral Training Award (PC151088), the Steven Spielberg Discovery Fund in Prostate Cancer Research, a Young Investigator Award from the Prostate Cancer Foundation (PCF), the St. Anthony 
Prostate Cancer Research Fund, the CD McKinnon Memorial Fund for Neuroendocrine Prostate Cancer, and the Berns Family Fund. The research endeavors at UCLA were supported by a Creativity Award from PCF, the UCLA Prostate Cancer SPORE Program, research grants (R21 CA151159 and R33 CA157396) from the NIH/NCI Innovative Molecular Analysis Technologies (IMAT) Program, and the Innovative Research in Cancer Nanotechnology (U01 CA 198900) research grant from the NIH/NCI Alliance for Nanotechnology in Cancer program.

\section{References}

1. Hoshimoto S, Shingai T, Morton DL, Kuo C, Faries MB, Chong K, Elashoff D, Wang H-J, Elashoff RM, Hoon DSB. J Clin Oncol. 2012; 30:3819. [PubMed: 23008288]

2. Cristofanilli M, Budd GT, Ellis MJ, Stopeck A, Matera J, Miller MC, Reuben JM, Doyle GV, Allard WJ, Terstappen LW, Hayes DF. N Engl J Med. 2004; 351:781. [PubMed: 15317891]

3. Cohen SJ, Punt CJ, Iannotti N, Saidman BH, Sabbath KD, Gabrail NY, Picus J, Morse M, Mitchell E, Miller MC, Doyle GV, Tissing H, Terstappen LW, Meropol NJ. J Clin Oncol. 2008; 26:3213. [PubMed: 18591556]

4. Hofman V, Ilie MI, Long E, Selva E, Bonnetaud C, Molina T, Venissac N, Mouroux J, Vielh P, Hofman P. Int J Cancer. 2011; 129:1651. [PubMed: 21128227]

5. a) Danila DC, Heller G, Gignac GA, Gonzalez-Espinoza R, Anand A, Tanaka E, Lilja H, Schwartz L, Larson S, Fleisher M, Scher HI. Clin Cancer Res. 2007; 13:7053. [PubMed: 18056182] b) Shaffer DR, Leversha MA, Danila DC, Lin O, Gonzalez-Espinoza R, Gu B, Anand A, Smith K, Maslak P, Doyle GV, Terstappen LW, Lilja H, Heller G, Fleisher M, Scher HI. Clin Cancer Res. 2007; 13:2023. [PubMed: 17404082]

6. a) Alix-Panabieres C, Pantel K. Klin Lab Diagn. 2014; 4:60.b) Heitzer E, Auer M, Ulz P, Geigl JB, Speicher MR. Genome Med. 2013; 5:73. [PubMed: 23998943]

7. Sundaresan TK, Sequist LV, Heymach JV, Riely GJ, Janne PA, Koch WH, Sullivan JP, Fox DB, Maher R, Muzikansky A, Webb A, Tran HT, Giri U, Fleisher M, Yu HA, Wei W, Johnson BE, Barber TA, Walsh JR, Engelman JA, Stott SL, Kapur R, Maheswaran S, Toner M, Haber DA. Clin Cancer Res. 2016; 22:1103. [PubMed: 26446944]

8. Mohamed Suhaimi N-A, Foong Y-M, Lee DY-K, Phyo W-M, Cima I, Lee EX-W, Goh W-L, Lim WY, Chia K-S, Kong S-L, Gong M, Lim B, Hillmer AM, Koh P-K, Ying JY, Tan M-H. Mol Oncol. 2015; 9:850. [PubMed: 25605225]

9. Robinson D, Van Allen EM, Wu Y-M, Schultz N, Lonigro RJ, Mosquera JM, Montgomery B, Taplin M-E, Pritchard CC, Attard G, Beltran H, Abida W, Bradley RK, Vinson J, Cao X, Vats P, Kunju LP, Hussain M, Feng FY, Tomlins SA, Cooney KA, Smith DC, Brennan C, Siddiqui J, Mehra R, Chen Y, Rathkopf DE, Morris MJ, Solomon SB, Durack JC, Reuter VE, Gopalan A, Gao J, Loda M, Lis RT, Bowden M, Balk SP, Gaviola G, Sougnez C, Gupta M, Yu EY, Mostaghel EA, Cheng HH, Mulcahy H, True LD, Plymate SR, Dvinge H, Ferraldeschi R, Flohr P, Miranda S, Zafeiriou Z, Tunariu N, Mateo J, Perez-Lopez R, Demichelis F, Robinson BD, Schiffman M, Nanus DM, Tagawa ST, Sigaras A, Eng KW, Elemento O, Sboner A, Heath EI, Scher HI, Pienta KJ, Kantoff P, de Bono JS, Rubin MA, Nelson PS, Garraway LA, Sawyers CL, Chinnaiyan AM. Cell. 2015; 161:1215. [PubMed: 26000489]

10. a) Sotiriou C, Pusztai L. N Engl J Med. 2009; 360:790. [PubMed: 19228622] b) Boström PJ, Bjartell AS, Catto JWF, Eggener SE, Lilja H, Loeb S, Schalken J, Schlomm T, Cooperberg MR. Eur Urol. 2015; 68:1033. [PubMed: 25913390]

11. a) Prensner JR, Iyer MK, Sahu A, Asangani IA, Cao Q, Patel L, Vergara IA, Davicioni E, Erho N, Ghadessi M, Jenkins RB, Triche TJ, Malik R, Bedenis R, McGregor N, Ma T, Chen W, Han S, Jing X, Cao X, Wang X, Chandler B, Yan W, Siddiqui J, Kunju LP, Dhanasekaran SM, Pienta KJ, Feng FY, Chinnaiyan AM. Nat Genet. 2013; 45:1392. [PubMed: 24076601] b) Prensner JR, Zhao S, Erho N, Schipper M, Iyer MK, Dhanasekaran SM, Magi-Galluzzi C, Mehra R, Sahu A, Siddiqui J, Davicioni E, Den RB, Dicker AP, Karnes RJ, Wei JT, Klein EA, Jenkins RB, Chinnaiyan AM, Feng FY. Lancet Oncol. 2014; 15:1469. [PubMed: 25456366]

12. a) Friedlander TW, Ngo VT, Dong H, Premasekharan G, Weinberg V, Doty S, Zhao Q, Gilbert EG, Ryan CJ, Chen WT, Paris PL. Int J Cancer. 2014; 134:2284. [PubMed: 24166007] b) Miyamoto DT, Lee RJ, Stott SL, Ting DT, Wittner BS, Ulman M, Smas ME, Lord JB, Brannigan BW, 
Trautwein J, Bander NH, Wu CL, Sequist LV, Smith MR, Ramaswamy S, Toner M, Maheswaran S, Haber DA. Cancer Discovery. 2012; 2:995. [PubMed: 23093251]

13. a) Antonarakis ES, Lu C, Wang H, Luber B, Nakazawa M, Roeser JC, Chen Y, Mohammad TA, Chen Y, Fedor HL, Lotan TL, Zheng Q, De Marzo AM, Isaacs JT, Isaacs WB, Nadal R, Paller CJ, Denmeade SR, Carducci MA, Eisenberger MA, Luo J. N Engl J Med. 2014; 371:1028. [PubMed: 25184630 ] b) Antonarakis ES, Lu C, Luber B, Wang H, Chen Y, Nakazawa M, Nadal R, Paller CJ, Denmeade SR, Carducci MA, Eisenberger MA, Luo J. JAMA Oncol. 2015; 1:582. [PubMed: 26181238]

14. Lin M, Chen J-F, Lu Y-T, Zhang Y, Song J, Hou S, Ke Z, Tseng H-R. Acc Chem Res. 2014; 47:2941. [PubMed: 25111636]

15. Chen J-F, Zhu YZ, Lu Y-T, Hodara E, Hou S, Agopian VG, Tomlinson JS, Posadas EM, Tseng HR. Theranostics. 2016; 6:1425. [PubMed: 27375790]

16. a) Reátegui E, Aceto N, Lim EJ, Sullivan JP, Jensen AE, Zeinali M, Martel JM, Aranyosi AJ, Li W, Castleberry S, Bardia A, Sequist LV, Haber DA, Maheswaran S, Hammond PT, Toner M, Stott SL. Adv Mater. 2015; 27:1593. [PubMed: 25640006] b) Park GS, Kwon H, Kwak DW, Park SY, Kim M, Lee JH, Han H, Heo S, Li XS, Lee JH, Kim YH, Lee JG, Yang W, Cho HY, Kim SK, Kim K. Nano Lett. 2012; 12:1638. [PubMed: 22364234] c) Chen JY, Tsai WS, Shao HJ, Wu JC, Lai JM, Lu SH, Hung TF, Yang CT, Wu LC, Chen JS, Lee WH, Chang YC. PLoS One. 2016; 11:e0149633. [PubMed: 26938471] d) Galanzha EI, Shashkov EV, Kelly T, Kim J-W, Yang L, Zharov VP. Nat Nanotechnol. 2009; 4:855. [PubMed: 19915570] e) Bai L, Du Y, Peng J, Liu Y, Wang Y, Yang Y, Wang C. J Mater Chem B. 2014; 2:4080.f) Liu X, Chen L, Liu H, Yang G, Zhang P, Han D, Wang S, Jiang L. NPG Asia Mater. 2013; 5:e63.g) He R, Zhao L, Liu Y, Zhang N, Cheng B, He Z, Cai B, Li S, Liu W, Guo S, Chen Y, Xiong B, Zhao X-Z. Biomed Microdevices. 2013; 15:617. [PubMed: 23780622] h) Myung JH, Gajjar KA, Saric J, Eddington DT, Hong S. Angew Chem, Int Ed. 2011; 50:11769.

17. Wang S, Wang H, Jiao J, Chen K-J, Owens GE, Kamei K, Sun J, Sherman DJ, Behrenbruch CP, Wu H, Tseng H-R. Angew Chem, Int Ed. 2009; 48:8970.

18. a) Groenendaal L, Jonas F, Freitag D, Pielartzik H, Reynolds JR. Adv Mater. 2000; 12:481.b) Groenendaal L, Zotti G, Aubert PH, Waybright SM, Reynolds JR. Adv Mater. 2003; 15:855.

19. a) Luo S-C, Liour SS, Yu H-h. Chem Commun. 2010; 46:4731.b) Zhao H, Zhu B, Sekine J, Luo SC, Yu H-h. ACS Appl Mater Interfaces. 2012; 4:680. [PubMed: 22211371] c) Zhao H, Zhu B, Luo S-C, Lin H-A, Nakao A, Yamashita Y, Yu H-h. ACS Appl Mater Interfaces. 2013; 5:4536. [PubMed: 23573953]

20. a) Luo S-C, Yu H-h, Wan ACA, Han Y, Ying JY. Small. 2008; 4:2051. [PubMed: 18949792] b) Luo S-C, Zhu B, Nakao A, Nakatomi R, Yu H-h. Adv Eng Mater. 2011; 13:B423.c) Luo S-C, Sekine J, Zhu B, Zhao H, Nakao A, Yu H-h. ACS Nano. 2012; 6:3018. [PubMed: 22424318] d) Luo S-C, Jiang J, Liour SS, Gao S, Ying JY, Yu H-h. Chem Commun. 2009; 45:2664.

21. Sekine J, Luo S-C, Wang S, Zhu B, Tseng H-R, Yu H-h. Adv Mater. 2011; 23:4788. [PubMed: 21954025]

22. a) Hsiao Y-S, Luo S-C, Hou S, Zhu B, Sekine J, Kuo C-W, Chueh D-Y, Yu H-h, Tseng H-R, Chen P. Small. 2014; 10:3012. [PubMed: 24700425] b) Hsiao Y-S, Ho B-C, Yan H-X, Kuo C-W, Chueh D-Y, Yu H-h, Chen P. J Mater Chem B. 2015; 3:5103.

23. Hou S, Zhao H, Zhao L, Shen Q, Wei KS, Suh DY, Nakao A, Garcia MA, Song M, Lee T, Xiong B, Luo S-C, Tseng H-R, Yu H-h. Adv Mater. 2013; 25:1547. [PubMed: 23255101]

24. Liu H, Liu X, Meng J, Zhang P, Yang G, Su B, Sun K, Chen L, Han D, Wang S, Jiang L. Adv Mater. 2013; 25:922. [PubMed: 23161781]

25. a) Ke Z, Lin M, Chen J-F, Choi J-S, Zhang Y, Fong A, Liang A-J, Chen S-F, Li Q, Fang W, Zhang P, Garcia AM, Lee T, Song M, Lin H-A, Zhao H, Luo S-C, Hou S, Yu H-h, Tseng H-R. ACS Nano. 2015; 9:62. [PubMed: 25495128] b) Lv SW, Wang J, Xie M, Lu NN, Li Z, Yan XW, Cai SL, Zhang PA, Dong WG, Huang WH. Chem Sci. 2015; 6:6432. [PubMed: 28757959] c) Lv SW, Liu Y, Xie M, Wang J, Yan XW, Li Z, Dong WG, Huang WH. ACS Nano. 2016; 10:6201. [PubMed: 27299807] d) Li W, Reátegui E, Park MH, Castleberry S, Deng JZ, Hsu B, Mayner S, Jensen AE, Sequist LV, Maheswaran S, Haber DA, Toner M, Stott SL, Hammond PT. Biomaterials. 2015; 65:93. [PubMed: 26142780] e) Yu X, He R, Li S, Cai B, Zhao L, Liao L, Liu 
W, Zeng Q, Wang H, Guo SS, Zhao XZ. Small. 2013; 9:3895. [PubMed: 23650272] f) Li W, Wang J, Ren J, Qu X. Adv Mater. 2013; 25:6737. [PubMed: 24123218]

26. a) Shen Q, Xu L, Zhao L, Wu D, Fan Y, Zhou Y, OuYang W-H, Xu X, Zhang Z, Song M, Lee T, Garcia MA, Xiong B, Hou S, Tseng H-R, Fang X. Adv Mater. 2013; 25:2368. [PubMed:

23495071] b) Li W, Wang J, Ren J, Qu X. Angew Chem, Int Ed. 2013; 52:6726.c) Zhang Z, Chen N, Li S, Battig MR, Wang Y. J Am Chem Soc. 2012; 134:15716. [PubMed: 22970862]

27. a) Springsteen G, Wang B. Tetrahedron. 2002; 58:5291.b) Li Y, Larsson EL, Jungvid H, Galaev IY, Mattiasson B. J Chromatogr, A. 2001; 909:137. [PubMed: 11269514]

28. a) Guimarda NK, Gomez N, Schmidt CE. Prog Polym Sci. 2007; 32:876.b) Kros A, Sommerdijk NAJM, Nolte RJM. Sens Actuators, B. 2005; 106:289.

29. Luo S-C, Ali EM, Tansil NC, Yu H-h, Gao S, Kantchev EA, Ying JY. Langmuir. 2008; 24:8071. [PubMed: 18588322]

30. a) Luo S-C, Xie H, Chen N, Yu H-h. ACS Appl Mater Interfaces. 2009; 1:1414. [PubMed: 20355943] b) Lin P, Yan F, Yu J, Chan HLW, Yang M. Adv Mater. 2010; 22:3655. [PubMed: 20661950] c) Tansil NC, Kantchev EAB, Gao Z, Yu H-h. Chem Commun. 2011; 47:1533.d) Xie H, Luo S-C, Yu H-h. Small. 2009; 5:2611. [PubMed: 19725044]

31. a) Abidian MR, Ludwig KA, Marzullo TC, Martin DC, Kipke DR. Adv Mater. 2009; 21:3764. [PubMed: 26345408] b) Isaksson J, Kjaell P, Nilsson D, Robinson N, Berggren M, RichterDahlfors A. Nat Mater. 2007; 6:673. [PubMed: 17643105]

32. Luo S-C, Kantchev EAB, Zhu B, Siang YW, Yu H-h. Chem Commun. 2012; 48:6942.

33. Liu H, Li Y, Sun K, Fan J, Zhang P, Meng J, Wang S, Jiang L. J Am Chem Soc. 2013; 135:7603. [PubMed: 23601154]

34. Zhu B, Luo S-C, Zhao H, Lin H-A, Sekine J, Nakao A, Chen C, Yamashita Y, Yu H-h. Nat Commun. 2014; 5:4523. [PubMed: 25060339]

35. Moreno JG, Croce CM, Fischer R, Monne M, Vihko P, Mulholland SG, Gomella LG. Cancer Res. 1992; 52:6110. [PubMed: 1382851]

36. Cardillo MR, Di Silverio F, Gentile V. Scand J Clin Lab Invest. 2004; 64:687. [PubMed: 15513326]

37. Zhang L, Wang C-Y, Yang R, Shi J, Fu R, Chen L, Klocker H, Zhang J. Urol Oncol. 2008; 26:634. [PubMed: 18367130]

38. a) Scher HI, Lu D, Schreiber NA, Louw J, Graf RP, Vargas HA, Johnson A, Jendrisak A, Bambury R, Danila D, McLaughlin B, Wahl J, Greene SB, Heller G, Marrinucci D, Fleisher M, Dittamore R. JAMA Oncol. 2016; 2:1441. [PubMed: 27262168] b) Qu F, Xie W, Nakabayashi M, Zhang H, Jeong SH, Wang X, Komura K, Sweeney CJ, Sartor O, Lee GSM, Kantoff PW. Clin Cancer Res. 2017; 23:726. [PubMed: 27489290]

39. Nakazawa M, Lu C, Chen Y, Paller CJ, Carducci MA, Eisenberger MA, Luo J, Antonarakis ES. Ann Oncol. 2015; 26:1859. [PubMed: 26117829] 
a)

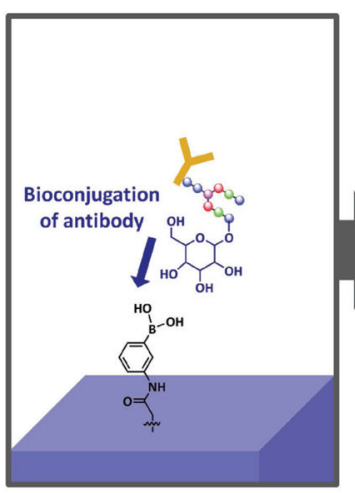

c)

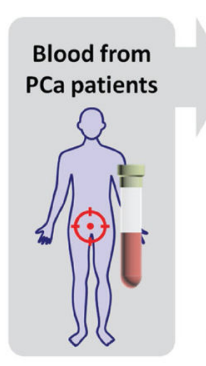

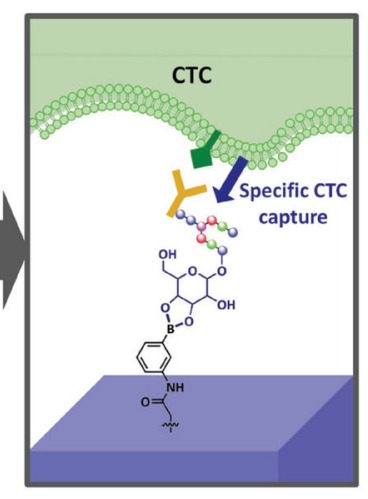

CTC capture and glycan-stimulated release

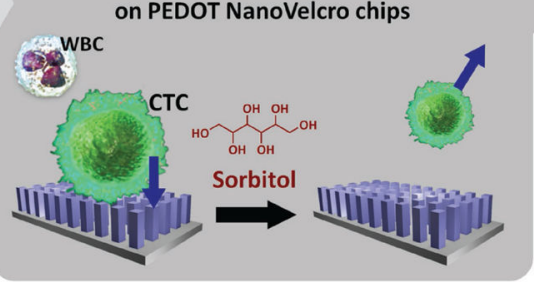

b)

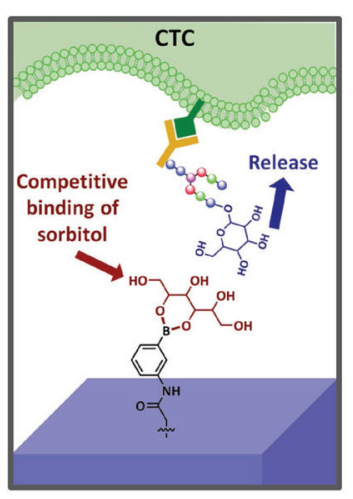

\section{Expression analyses} of RNA biomarkers

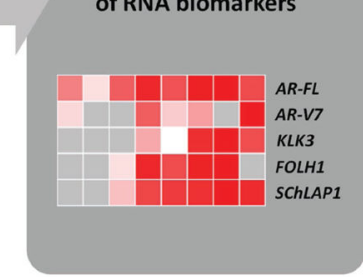

Figure 1.

Illustration on the main research scheme. a) The mechanism for circulating tumor cell (CTC) capture is that the surface-grafted phenylboronic acid (PBA) conjugates with antibody, subsequently enabling specific CTC capture. b) The mechanism for CTC release is that the introduction of glycan with stronger affinity to PBA (i.e., sorbitol) results in competitive binding, allowing CTC release. c) Workflow on using this glycan stimulation enabled CTC purification platform on poly(3,4-ethylenedioxythiophene) (PEDOT) NanoVelcro chips for RNA biomarker analysis from purified CTCs of prostate cancer (PCa) patients. 


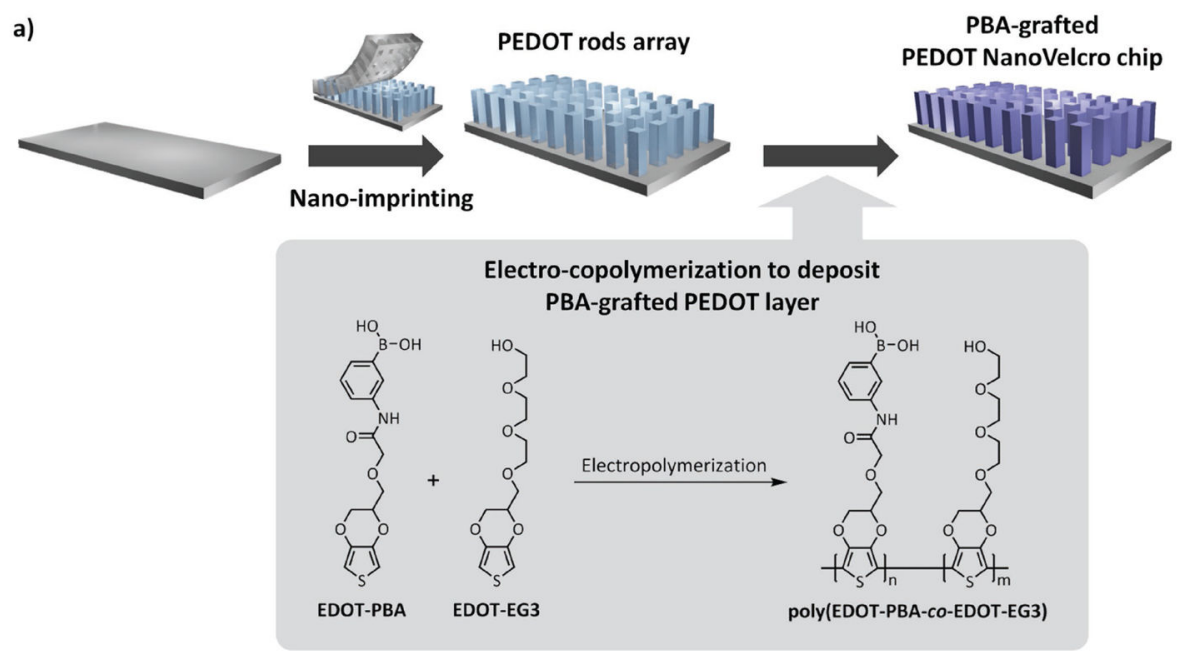

b)

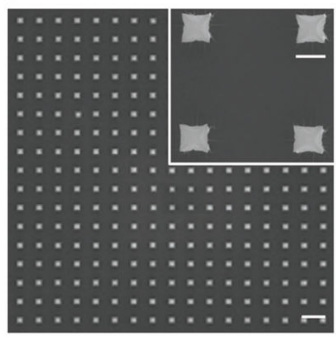

c)

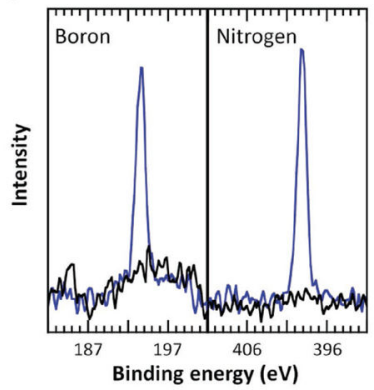

d)

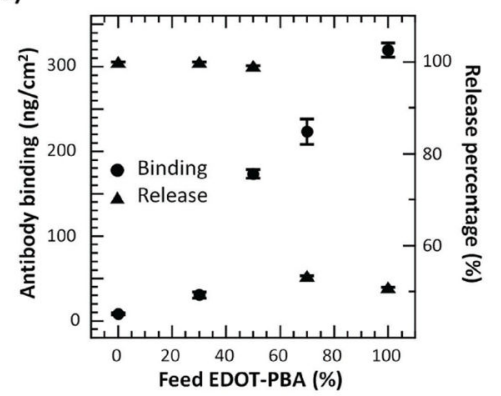

Figure 2.

Materials synthesis and characterization of PBA-grafted PEDOT NanoVelcro chips. a) Schematic representation on the chip fabrication and electropolymerization to deposit the PBA-grafted poly(EDOT-PBA-co-EDOT-EG3). EDOT-EG3 was used to reduce nonspecific interactions for specific CTC capture and EDOT-PBA was used to introduce the grafted PBA groups. c) SEM images of the PEDOT rods array structure. The length of the scale bar in the image was 5 and $1 \mu \mathrm{m}$ (enlarged), respectively. d) X-ray photoelectron spectra of nanoimprinted PEDOT rods array (black) and PBA-grafted PEDOT NanoVelcro chip (blue) in boron 1s and nitrogen 1s regions. e) Binding (circle) and sorbitol-stimulated release (triangle) of anti-EpCAM on top of poly(EDOT-PBA-co-EDOT-EG3) films examined by quartz crystal microbalance measurements ( $n=3$ for each data point). 
a)

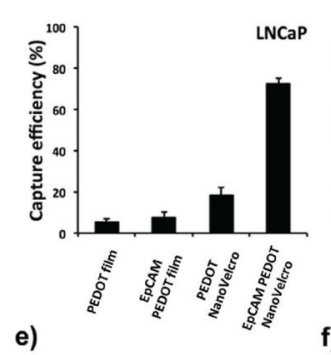

b)

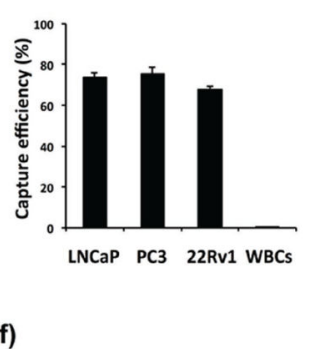

c)

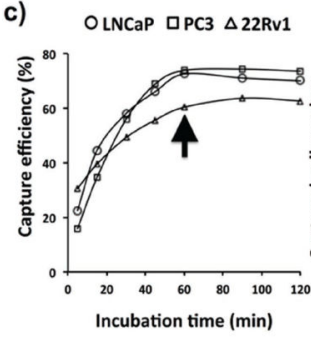

g)

g)

d) OLNCaP QPC3 $\triangle 22 \mathrm{Rv} 1$
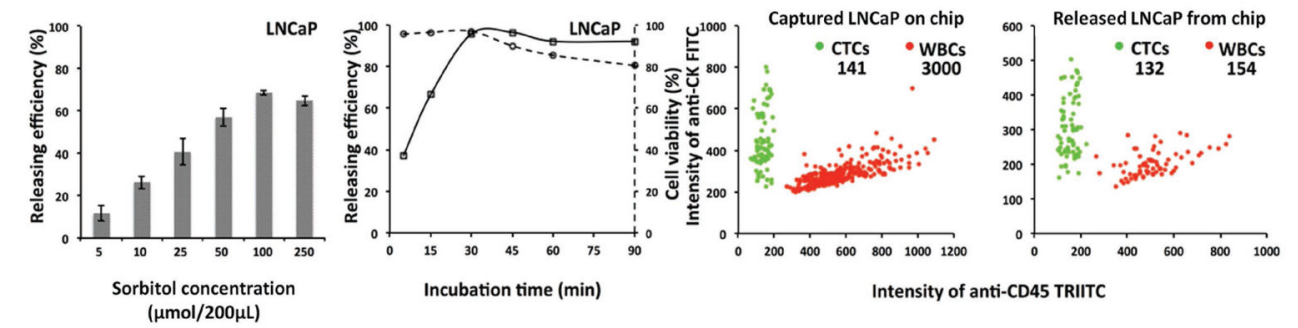

Figure 3.

Optimization of PEDOT NanoVelcro chips based CTC purification assay. a) Synergistic effect of anti-EpCAM and PEDOT NanoVelcro chips largely enhanced the capture efficiency of prostate cancer (PCa) cells. The anti-EpCAM-conjugated chip (labeled as EpCAM PEDOT NanoVelcro) yielded the highest capture efficiency for EpCAM-positive LNCaP cells $(n=3)$. b) Capturing efficiency of anti-EpCAM-conjugated PEDOT NanoVelcro chips is significantly higher for EpCAM-positive PCa cells (LNCaP, PC3, and 22Rv1) than that for EpCAM-negative cells (white blood cells, WBCs) ( $n=3$ for each group). c) Capturing efficiency on the new PEDOT NanoVelcro was dependent on the incubation time. The efficiency for PCa cell lines ( $\mathrm{LNCaP}, \mathrm{PC} 3$, and 22Rv1) plateaued at 60 min. d) Capturing efficiency remained constant at different cell number ranging from 1 to 2000 cells. Regression analysis showed linear correlation with capturing efficiency consistent with (c). e) Releasing efficiency of PEDOT NanoVelcro chips was dependent on sorbitol concentration. The highest releasing efficiency occurred at $100 \mu \mathrm{mol} / 200 \mu \mathrm{L}(0.5$ M) $(n=3)$. f) Incubation time with sorbitol affected the releasing efficiency of PEDOT NanoVelcro chips and the cellular viability. An incubation time of 30 min provided optimal cellular viability (95\%) and releasing efficiency (96\%). g) Scatter plot showed the composition of cells captured on PEDOT-NanoVelcro substrates during a representative spiking study with $200 \mathrm{LNCaP}$ cells spiked into 1 million WBCs. Three-color immunocytochemistry method based on FITC-labeled anti-Cytokeratin, TRITC-labeled antiCD45, and DAPI nuclear staining was applied to identify and enumerate CTCs from nonspecifically trapped WBCs. (Left) After cell capturing process, LNCaP cells were captured by an efficiency of $71 \%$ compared to $0.3 \%$ for WBCs. (Right) After incubating with sorbitol, $94 \%$ of $\mathrm{LNCaP}$ could be released compared to $5.1 \%$ for WBCs. The purity of cancer cells was enhanced from 0.02 to $46 \%$ after the capturing-releasing process. 


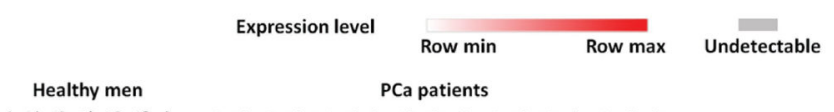
Healthy men

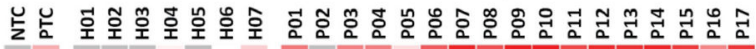
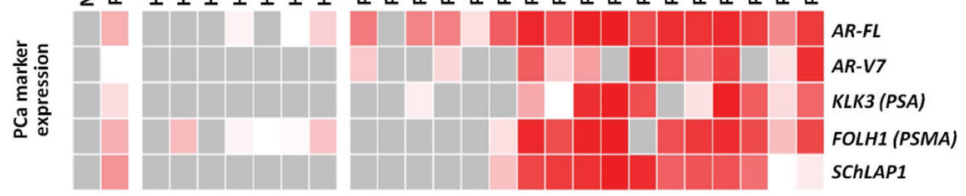

b)

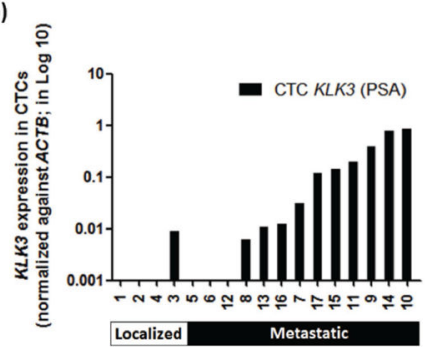

c)

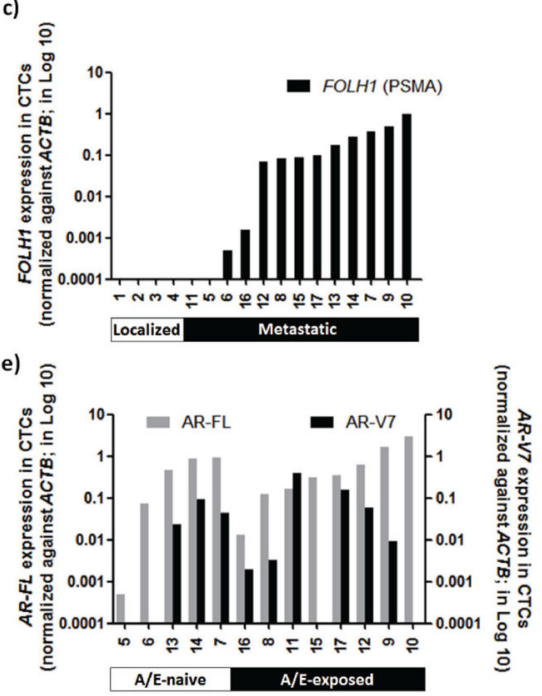

Figure 4.

Detection of PCa-related RNA signatures in CTCs purified by PEDOT NanoVelcro Chips. a) Summary of RNA signature detection in 7 healthy men and $17 \mathrm{PCa}$ patients. PTC $=$ positive control (RNA from 100 LNCaP cells + 100 22Rv1 cells in 1 million WBCs from a healthy man purified by PEDOT-NanoVelcro Chips); NTC = negative control (nuclease free water).

b) $K L K 3$ gene expression in CTCs. The expression of $K L K 3$ gene was more commonly seen in metastatic PCa with $77 \%$ (10/13) of the metastatic patients showing positive signal compared to only $25 \%$ (1/4) nonmetastatic PCa patient having detectable expression. c) FOLH1 gene expression in CTCs was only detected in metastatic PCa patients with $85 \%$ (11/13) of the metastatic PCa patients having detectable expression. d) SChLAP1 expression in CTCs was only detected in metastatic PCa patients with $92 \%(12 / 13)$ of the metastatic PCa patients having detectable expression. e) Expression of $A R-F L$ and $A R-V 7$ in CTCs. $A R-V 7$ can be detected in $6 / 8$ metastatic PCa patients who had been exposed to abiraterone (A) or enzalutamide (E), and was accompanied with the expression of $A R-F L$. Some (3/5) patients who had not received $\mathrm{A} / \mathrm{E}$ treatment also showed positive $A R$ - $V 7$ signals. All expression levels were normalized against $A C T B$. 